\title{
Hepatocyte growth factor (HGF) and stem cell factor (SCF) maintained the stemness of human bone marrow mesenchymal stem cells (hBMSCs) during long-term expansion by preserving mitochondrial function via the PI3K/AKT, ERK1/2, and STAT3 signaling pathways
}

Zeyuan Cao ${ }^{\dagger}$, Yunyi Xie ${ }^{\dagger}$, Le Yu, Yi Li and Yan Wang ${ }^{*}$ (D)

\begin{abstract}
Background: Mesenchymal stem cells (MSCs) have a limited self-renewal ability, impaired multi-differentiation potential, and undetermined cell senescence during in vitro series expansion. To address this concern, we investigated the effects of the microenvironment provided by stem cells from human exfoliated deciduous teeth (SHED) in maintaining the stemness of human bone marrow mesenchymal stem cells (hBMSCs) and identified the key factors and possible mechanisms responsible for maintaining the stemness of MSCs during long-term expansion in vitro.

Methods: The passage 3 (P3) to passage 8 (P8) hBMSCs were cultured in the conditioned medium from SHED (SHED-CM). The percentage of senescent cells was evaluated by $\beta$-galactosidase staining. In addition, the osteogenic differentiation potential was analyzed by reverse transcription quantitative PCR (RT-qPCR), Western blot, alizarin red, and alkaline phosphatase (ALP) staining. Furthermore, RT-qPCR results identified hepatocyte growth factor (HGF) and stem cell factor (SCF) as key factors. Thus, the effects of HGF and SCF on mitochondrial function were assessed by measuring the ROS and mitochondrial membrane potential levels. Finally, selected mitochondrialrelated proteins associated with the PI3K/AKT, ERK1/2, and STAT3 signaling pathways were investigated to determine the effects of HGF and SCF in preserving the mitochondrial function of hBMSCs during long-term expansion.

\footnotetext{
* Correspondence: wang93@mail.sysu.edu.cn

†Zeyuan Cao and Yunyi Xie contributed equally to this work.

Hospital of Stomatology, Guanghua School of Stomatology, Guangdong

Provincial Key Laboratory of Stomatology, Sun Yat-sen University, 56

Lingyuanxi Road, Guangzhou 510055, China
}

C C The Author(s). 2020 Open Access This article is licensed under a Creative Commons Attribution 4.0 International License, which permits use, sharing, adaptation, distribution and reproduction in any medium or format, as long as you give appropriate credit to the original author(s) and the source, provide a link to the Creative Commons licence, and indicate if changes were made. The images or other third party material in this article are included in the article's Creative Commons licence, unless indicated otherwise in a credit line to the material. If material is not included in the article's Creative Commons licence and your intended use is not permitted by statutory regulation or exceeds the permitted use, you will need to obtain permission directly from the copyright holder. To view a copy of this licence, visit http://creativecommons.org/licenses/by/4.0/. The Creative Commons Public Domain Dedication waiver (http://creativecommons.org/publicdomain/zero/1.0/) applies to the data made available in this article, unless otherwise stated in a credit line to the data. 


\begin{abstract}
(Continued from previous page)
Results: SHED-CM had significantly enhanced the cell proliferation, reduced the senescent cells, and maintained the osteogenesis and pro-angiogenic capacity in P8 hBMSCs during long-term expansion. In addition, hBMSCs treated with $100 \mathrm{ng} / \mathrm{ml} \mathrm{HGF}$ and $10 \mathrm{ng} / \mathrm{ml}$ SCF had reduced ROS levels and preserved mitochondrial membrane potential compared with P8 hBMSCs during long-term expansion. Furthermore, HGF and SCF upregulated the expression of mitochondrial-related proteins associated with the PI3KJAKT, ERK1/2, and STAT3 signaling pathways, possibly contributing to the maintenance of hBMSCs stemness by preserving mitochondrial function.
\end{abstract}

Conclusion: Both HGF and SCF are key factors in maintaining the stemness of hBMSCs by preserving mitochondrial function through the expression of proteins associated with the PI3K/AKT, ERK1/2, and STAT3 signaling pathways. This study provides new insights into the anti-senescence capability of HGF and SCF, as well as new evidence for their potential application in optimizing the long-term culture of MSCs.

Keywords: Stem cells from human exfoliated deciduous teeth, Hepatocyte growth factor, Stem cell factor, Stemness, Senescence, Osteogenic differentiation, Mitochondrial function

\section{Introduction}

In recent years, several studies have focused on the various therapeutic applications of mesenchymal stem cells (MSCs), including cell transplantation for cartilage and bone repair [1,2] and neuronal regeneration [3, 4], due to their ability to self-renew and differentiate into a variety of cell types. Furthermore, due to their low immunogenicity and ability to secrete immune factors or cytokines [5, 6], MSCs have been studied and utilized in clinical trials for some immune-related diseases, such as chronic graft versus host diseases (cGVHD) [7] and Crohn's disease [8].

The number of MSCs available is limited by the donor tissues or organs. Hence, the expansion of MSCs in vitro is necessary. However, their unpredictable differentiation, senescence, and loss of stemness during in vitro culture reduce their effectiveness and create unknown risks $[9,10]$. In particular, the human bone marrow mesenchymal stem cells (hBMSCs) are difficult to expand in vitro and prone to cell aging, possibly due to the difficulty of simulating their growth environment in vivo $[11,12]$. Stem cells reside in a specific microenvironment called the stem cell niche. This microenvironment consists of the extracellular matrix (ECM) and neighboring cells, such as endothelial, fibroblast, and other progenitor cells [13]. In addition, the stem cells essentially contribute a large number of bioactive molecules, such as cytokines, chemokines, angiogenic factors, and growth factors to the niche. The stem cell niche, which is maintained by a continuous communication between the stem cells and the surrounding cells through cell signaling or the paracrine effects, determines stem cell fate to maintain a balance of self-renewal and differentiation and influences cell senescence or apoptosis [14-16].

It is necessary to devise a way to maintain the stemness of MSCs during long-term expansion and simultaneously produce MSCs in sufficient quantity for therapeutic purposes. Previous studies have addressed this problem by mimicking the in vivo stem cell niche to optimize cell culture conditions and prepare a sufficient quantity of qualified pluripotent stem cells. Currently, there are several methods to maintain the stemness of MSCs. For example, many biomaterials have been invented to promote the proliferation and self-renewal ability of MSCs. Some of these biomaterials contain laminin, collagen, and fibronectin, which are the primary composition of the ECM $[17,18]$. On the other hand, $3 \mathrm{D}$ cell culture models provide additional dimensions for cell adhesion and mimic in vivo cell morphology and molecular control [19]. In addition, co-culture systems with other cell types, such as endothelial progenitor cells [20] are considered into cell culture gradually for mimic an in vivo cellular niche, which have gotten some notable effect.

Several studies have observed that stem cells from human exfoliated deciduous teeth (SHED) have significantly better and more sustained ability to proliferate and resist senescence than hBMSCs [21, 22]. In addition, as the factors secreted by MSCs have a crucial role in maintaining their stemness, we speculate that this may also be true for SHED. Therefore, we hypothesized that hBMSCs cultured using SHED-CM in vitro may afford them with enhanced proliferative and self-renewal properties during long-term expansion. The secretions of SHED were also investigated further to identify the key factors and possible mechanisms associated with the stemness of hBMSCs and potentially devise a new method to optimize the long-term expansion of MSCs in vitro.

\section{Methods and materials \\ Cell isolation and culture}

SHED were isolated and collected from non-caries exfoliated human deciduous teeth (4-10 years old; 6 males and 6 females, without oral or systematic diseases) after informed consent and approved by the Ethics Committee of 
Hospital of Stomatology in Sun Yat-sen University. Briefly, the pulps from deciduous teeth were minced and digested with $3 \mathrm{mg} / \mathrm{ml}$ collagenase type I and $4 \mathrm{mg} / \mathrm{ml}$ dispase (Gibco-BRL, USA) and cultured using DMEM (GibcoBRL, USA) that contained $10 \%$ FBS, 100 units $/ \mathrm{ml}$ streptomycin (HyClone, USA), and $100 \mathrm{units} / \mathrm{ml}$ penicillin (HyClone, USA). hBMSCs at passage 2 (P2) were bought from Cyagen Biosciences (China), from healthy adults (18-45 years old), and cultured using DMEM that contained 10\% FBS, 100 units $/ \mathrm{ml}$ streptomycin, and 100 units/ml penicillin. Human umbilical vein endothelial cells (HUVECs) were bought from the China Center for Type Culture Collection (CCTCC, China) and cultured using endothelial cell medium (ECM, ScienCell, USA) that contained 5\% FBS, 100 units/ml streptomycin, and 100 units/ $\mathrm{ml}$ penicillin. Hepatocyte growth factor (HGF), stem cell factor (SCF), and insulin-like growth factor 2 (IGF2) (all from PeproTech, USA) were supplemented into DMEM during the long-term expansion of hBMSCs from passage 3 (P3) to passage 8 (P8). LY294002 (Sigma-Aldrich), U0126 (MedChemExpress), and Stattic (MedChemExpress) were separately added to the culture medium to block PI3K/AKT, ERK1/2, and STAT3 signaling pathways.

\section{Supernatant collection}

SHED (P3) or hBMSCs (P3) were seeded into a $10-\mathrm{cm}$ dish $\left(4 \times 10^{5}\right.$ cells per dish $)$ and cultured in DMEM that contained 10\% FBS for 3 days. The supernatants of SHED or hBMSCs were collected (centrifuged at $800 \mathrm{~g}$ for $5 \mathrm{~min}$ to remove cell debris) and preserved at $80^{\circ} \mathrm{C}$. For supplying enough nutrition to cells, the supernatants were mixed with fresh DMEM that contained $10 \%$ FBS in a 1:1 ratio when used, named as conditioned medium from SHED (SHED-CM) or conditioned medium from hBMSCs (hBMSCs-CM). To explore the effect of conditioned mediums on stemness and senescence of hBMSCs during long-term expansion, hBMSCs were cultured in DMEM, SHED-CM, or hBMSCs-CM from $\mathrm{P} 3$ to $\mathrm{P} 8$, respectively.

\section{Colony-forming unit (CFU) assay}

To detect the effect of conditioned mediums on the selfrenewal ability of hBMSCs (P3), 1000 cells were seeded into a 10-cm dish in each group and cultured in DMEM that contained 10\% FBS, SHED-CM, or hBMSCs-CM for 14 days. hBMSCs were washed with PBS, fixed with $4 \%$ paraformaldehyde (PFA), and stained with $0.1 \%(\mathrm{w} / \mathrm{v})$ crystal violet (Sigma, USA).

\section{Cell cycle analysis}

hBMSCs in each group (P3, P8, P8-SHED-CM and P8hBMSCs-CM) were seeded into 6-well culture plates $\left(5 \times 10^{4}\right.$ cells per well) and collected after 3 days. Cells were washed with cold PBS and fixed in 70\% ethanol overnight at $4{ }^{\circ} \mathrm{C}$. After being washed with cold PBS, cells were incubated with $50 \mu \mathrm{g} / \mathrm{ml}$ propidium iodide (PI), $100 \mu \mathrm{g} / \mathrm{ml}$ ribonuclease $\mathrm{A}$, and $0.1 \%$ TritonX-100 in PBS at $4{ }^{\circ} \mathrm{C}$ for $30 \mathrm{~min}$ and detected by flow cytometry (Beckman Coulter, Germany). Data were analyzed by Flowjo software. The Dean-Jett-Fox model was used to calculate the cell cycle phases.

\section{$\beta$-Galactosidase staining}

hBMSCs in each group (P3, P8, P8-SHED-CM and P8hBMSCs-CM) were seeded into 6-well culture plates $\left(5 \times 10^{4}\right.$ cells per well) and cultured for 3 days. Senescent cells were stained by a $\beta$-galactosidase $(\beta$-gal) staining kit (Beyotime, China) according to the manufacturer's instructions. The $\beta$-gal-positive cells were scanned by microscopy, and 6 fields were taken to calculate the proportion of senescent cells in each group.

\section{Osteogenic induction}

For RT-qPCR and Western blot assay, hBMSCs in each group were cultured into 6 -well plates $\left(5 \times 10^{4}\right.$ cells per well) for 3 days, followed by induced with osteogenic differentiation medium (DMEM that contained 10\% FBS, $10 \mathrm{mM} \beta$-glycerophosphate, $10 \mathrm{nM}$ dexamethasone, and $50 \mu \mathrm{g} / \mathrm{mL}$ ascorbic acid) for 7 days. For alizarin red and alkaline phosphatase (ALP) staining, hBMSCs in each group were cultured into 24 -well plates $\left(1 \times 10^{4}\right.$ cells per well) for 3 days, followed by induced with osteogenic differentiation medium for 14 days. P3 hBMSCs without osteogenic induction were named as "P3", with induction named as "P3+". Similarly, other groups were named by the same way (as P8, P8+, P8-SHED-CM+, P8-hBMSCs-CM+).

\section{Total RNA extraction and reverse transcription quantitative PCR (RT-qPCR)}

Total RNA of cells was isolated with RNA isolation kit (Ultrapure RNA Kit, CW Biotech, China) and transcribed into cDNA using Reverse Transcriptase M-MLV kit (TaKaRa, China). RT-qPCR assay was performed according to the manufacturer's instructions of SYBR Green PCR Master Mix kit (Roche, Switzerland). GAPD $\mathrm{H}$ was used as the internal control. The cycling conditions were all as follows: incubation at $95^{\circ} \mathrm{C}$ for $10 \mathrm{~min}$, 40 cycles of denaturation at $95^{\circ} \mathrm{C}$ for $15 \mathrm{~s}$, annealing at $60{ }^{\circ} \mathrm{C}$ for 20 s, and extension at $72{ }^{\circ} \mathrm{C}$ for 20 s. The primer sequences for each gene are listed in Table 1. The expression level of targeted gene was analyzed by $2^{-\Delta \Delta C t}$ method.

\section{Western blot analysis}

Cells were harvested and lysed in RIPA $(50 \mathrm{mM}$ Tris- $\mathrm{HCl}$ $\mathrm{pH}$ 7.4, $150 \mathrm{mM} \mathrm{NaCl}, \quad 1 \%$ TritonX-100, $0.5 \%$ sodium 
Table 1 Primer sequences used in reverse transcription quantitative PCR (RT-qPCR)

\begin{tabular}{ll}
\hline Gene & Sequence \\
\hline p16 & Forward: 5'-CCCCTTGCCTGGAAAGATAC-3' \\
& Reverse: 5'-AGCCCCTCCTCTTCTTCCT-3' \\
p21 & Forward: 5'-AGCAGCGGAACAAGGAGT-3' \\
& Reverse: 5'-TTACAGTCTAGGTGGAGAAACG-3' \\
Nanog & Forward: 5'-AAGGCCTCAGCACCTACCTA-3' \\
& Reverse: 5'-TGCACCAGGTCTGAGTGTTC-3' \\
OCT4 & Forward: 5'-TGGATGTCAGGGCTCTTTGTC-3' \\
& Reverse: 5'-ACCTTCCCAAATAGAACCCCC-3' \\
Runx2 & Forward: 5'-TGGTTACTGTCATGGCGGGTA-3' \\
& Reverse: 5'-TCTCAGATCGTTGAACCTTGCTA-3' \\
BSP & Forward: 5'-GAACCACTTCCCCACCTTTG-3' \\
& Reverse: 5'-ATTCTGACCATCATAGCCATCG-3' \\
ALP & Forward: 5'-TTCAAACCGAGATACAAGCACT-3' \\
& Reverse: 5'-GGGCCAGACCAAAGATAGAG-3' \\
GAPDH & Forward: 5'-GGAGCGAGATCCCTCCAAAAT-3' \\
& Reverse: 5'-GGCTGTTGTCATACTTCTCATGG-3' \\
&
\end{tabular}

deoxycholate, $0.1 \%$ SDS, and protease inhibitor cocktail) on ice for $30 \mathrm{~min}$. Total protein concentrations were measured by a BCA protein assay kit (Pierce, Thermo Scientific). Western blot assay was performed using protocols described below. Briefly, $40 \mu \mathrm{g}$ total protein was separated by $10 \%$ sodium dodecyl sulfate polyacrylamide gel electrophoresis (SDS-PAGE), transferred onto nitrocellulose (NC) membranes, blocked by $5 \%(\mathrm{w} / \mathrm{v})$ nonfat milk for $1 \mathrm{~h}$ at room temperature and then incubated with primary antibodies specific for Runx2 (ABclonal, 1:500), BSP (Boster, 1: 200), Mitofusin 1 (Mfn1, Boster, 1:200), Mitofusin 2 (Mfn2, Boster, 1:200), Catalase (Cell Signaling Technology, 1:1000), SOD2 (Cell Signaling Technology, 1:1000), PI3K (Boster, 1: 200), phospho-AKT (p-AKT, Cell Signaling Technology, 1: 1000), AKT (Cell Signaling Technology, 1:1000), phosphoERK1/2 (p-ERK1/2, Cell Signaling Technology, 1:2000), Erk1/2 (Cell Signaling Technology, 1:1000), phosphoSTAT3 (p-STAT3, Cell Signaling Technology, 1:2000), STAT3 (ABclonal, 1:2000), and $\beta$-actin (Sigma 1:5000) overnight at $4{ }^{\circ} \mathrm{C}$. After being incubated with secondary antibodies for $1 \mathrm{~h}$ at room temperature, the membranes were scanned by an Odyssey two-color infrared laser imaging system (LI-COR Biosciences, USA). Relative protein expression levels were analyzed by Image J software and normalized to $\beta$-actin.

\section{Alizarin red and ALP staining}

For alizarin red staining (ARS), hBMSCs in each group (P3, $\mathrm{P} 3+$, P8, P8+, P8-SHED-CM+, and P8-hBMSCs-CM+) were fixed with $4 \%$ PFA and stained with $1 \%(\mathrm{w} / \mathrm{v})$ Alizarin Red. The nodules were scanned by microscopy and dissolved by $10 \%(\mathrm{w} / \mathrm{v})$ cetylpyridinium chloride (Sigma, USA). OD values were measured at $562 \mathrm{~nm}$. ALP staining was performed by the BCIP/NBT Alkaline Phosphatase Color Development Kit (Beyotime Biotech, China), according to the manufacturer's instructions.

\section{Cell proliferation detection}

The effect of HGF, SCF, and IGF2 on the proliferation ability of hBMSCs was detected using CFSE assay. hBMSCs (P3) were labeled with $1 \mu \mathrm{M}$ of CFSE (Invitrogen, USA) before culture; then, cells were seeded into 6well plates $\left(5 \times 10^{4}\right.$ cells per well) and cultured in DMEM supplemented with different factors at different concentrations for 3 days. The proliferative cell rate was detected by flow cytometry (CytoFLEX, Beckman Coulter). Data were analyzed by Flowjo software.

\section{Assessment of ROS production}

hBMSCs in each group (P3, P8, P8-SHED-CM, P8-HGF 100, P8-SCF 10 and P8-H+S) were seeded into 6-well culture plates $\left(5 \times 10^{4}\right.$ cells per well) and cultured for 3 days. Intracellular ROS was detected by fluorescence probe DCFH-DA (Sigma, USA) according to the manufacturer's protocol. Briefly, cells were incubated with $10 \mu \mathrm{M}$ DCFH-DA in dark at $37^{\circ} \mathrm{C}$ for $20 \mathrm{~min}$, then washed by PBS and observed under fluorescence microscope (Cael Zeiss, Oberkochen, Germany). As a positive control, hBMSCs in passage 3 (P3) were incubated with $1 \mathrm{mM} \mathrm{H}_{2} \mathrm{O}_{2}$ for $1 \mathrm{~h}$ prior to the detection $[23,24]$. As a negative control, DCFH-DA probe was replaced by an equal-volume of DMSO. To obtain quantitative result, the fluorescence intensity was detected by flow cytometry (CytoFLEX, Beckman Coulter). Data were analyzed with CytExpert Software (Beckman Coulter).

\section{Mitochondrial membrane potential assay}

hBMSCs in each group (P3, P8, P8-SHED-CM, P8-HGF 100, P8-SCF 10 and P8-H+S) were seeded into 6-well culture plates $\left(5 \times 10^{4}\right.$ cells per well $)$ and cultured for 3 days. Mitochondrial membrane potential was detected by a JC1 fluorescent probe assay kit (Beyotime Biotech, China) according to the manufacturer's protocol. Cell fluorescence was observed under fluorescence microscope (Cael Zeiss, Oberkochen, Germany). To obtain quantitative results, the fluorescence intensity was detected by flow cytometry (CytoFLEX, Beckman Coulter). Data were analyzed with CytExpert Software (Beckman Coulter).

\section{Statistical analysis}

All data were performed in biological triplicates and results were expressed as mean \pm SD. Statistical analysis was conducted using SPSS20.0 software package (SPSS Inc., Chicago, IL, USA). One-way analysis of variance (ANOVA) was used and post hoc Bonferroni test was 
performed for multiple comparisons. $P$ values $<0.05$ were considered statistically significant.

\section{Results}

hBMSCs cultured in SHED-CM had enhanced cell proliferation

CFU assay was performed to examine the effect of SHED$\mathrm{CM}$ on the self-renewal ability of hBMSCs. Results showed that hBMSCs cultured in SHED-CM had the highest colony number compared with hBMSCs cultured in DMEM and hBMSCs-CM, indicating that SHED-CM significantly enhanced the self-renewal of hBMSCs (Fig. 1a). The cell proliferation after long-term expansion from passage 3 (P3) to passage 8 (P8) in different conditioned mediums was detected by cell cycle assay. Results showed that about $80 \%$ hBMSCs had cell cycle arrest in $\mathrm{G0/G1}$ phase at $\mathrm{P} 8$, and the $\mathrm{S}$ phase population significantly decreased at P8 (12.4\%) compared with P3 (20.5\%) hBMSCs. SHED-CM treatment decreased the G0/G1 phase population to approximately $70 \%$ and induced the hBMSCs to undergo S phase (18.3\%) (Fig. 1b). These results demonstrated that SHED-CM can improve the proliferative and self-renewal abilities of hBMSCs during long-term expansion.

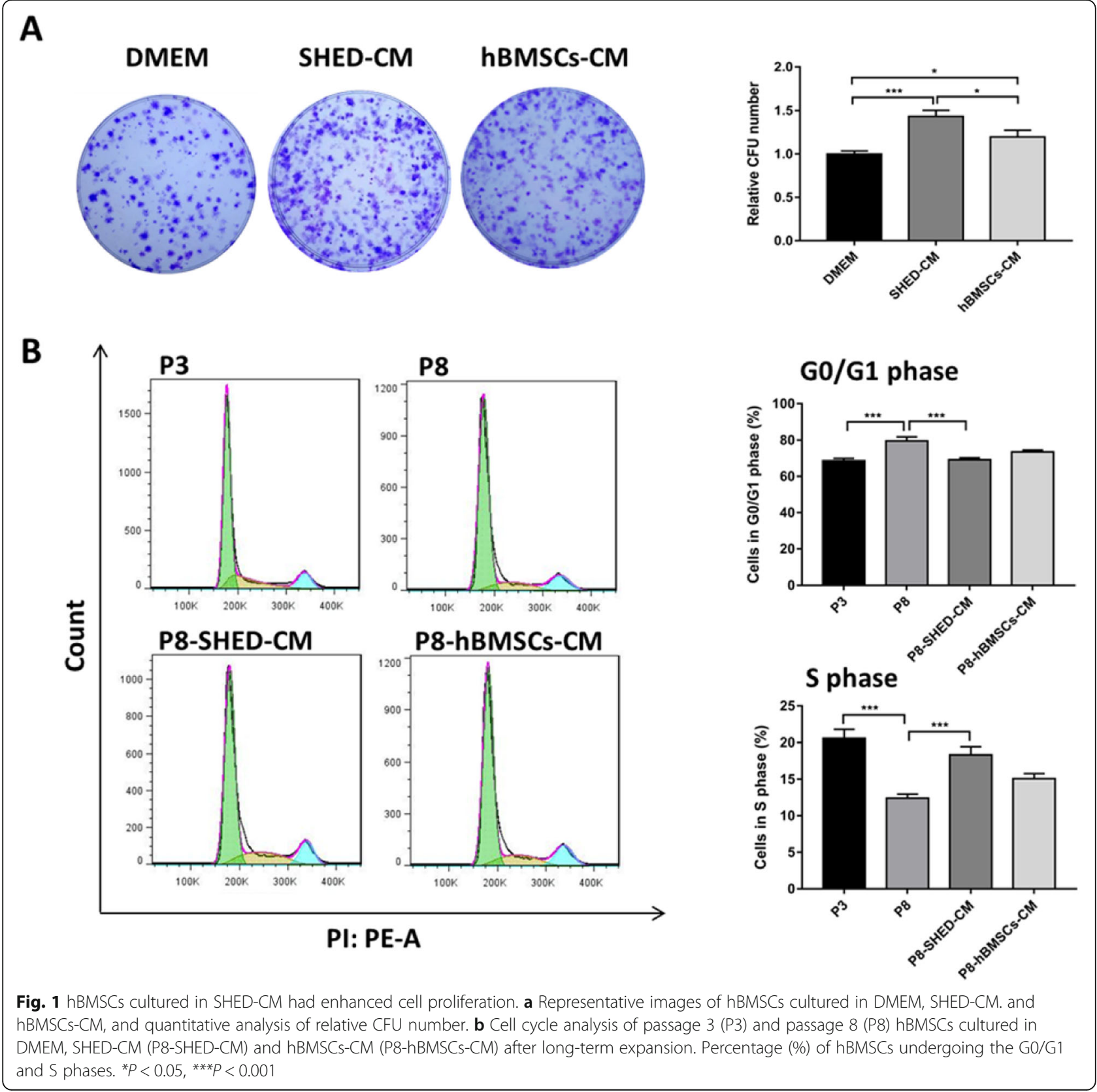


hBMSCs cultured in SHED-CM had less senescence and maintained stemness during long-term expansion After confirming that SHED-CM treatment can promote the proliferation and self-renewal of hBMSCs, we also determined the effects of the treatment in regulating the stemness and senescence of hBMSCs during long-term expansion. $\beta$-Galactosidase staining assay revealed that hBMSCs in P8-SHED-CM group had fewer $\beta$-gal-positive cells (17\%) than that in P8 hBMSCs (36.5\%) and P8hBMSCs-CM (30.1\%) groups (Fig. 2a). The mRNA expression levels of senescence ( $p 16$ and $p 21)$ and stemness (Nanog and OCT4) markers were analyzed using RT-qPCR. P8 hBMSCs had higher $p 16$ and $p 21$ expression levels and lower Nanog and OCT4 expression levels than P3 hBMSCs. The $p 16$ and $p 21$ expressions were significantly downregulated in P8-SHED-CM hBMSCs, while Nanog and OCT4 were significantly upregulated compared with P8 hBMSCs (Fig. 2b). These results indicated that SHED-CM can potentially delay cell senescence and maintain the stemness of hBMSCs during long-term expansion.

\section{hBMSCs cultured in SHED-CM had enhanced osteogenic differentiation potential during long-term expansion}

After osteogenic induction for 7 days, the mRNA expression levels of the osteogenic markers (Runx2, BSP, and $A L P)$ significantly increased in the P3+ group and significantly decreased in the P8+ group. Furthermore, the Runx2, $B S P$, and $A L P$ mRNA expression levels in the P8-SHED$\mathrm{CM}+$ group was significantly higher than the P8+ group (Fig. 3a). Western blot analysis revealed significantly decreased expression levels of the osteogenic-related proteins, Runx2, and BSP in P8+ group. Both proteins were highly expressed in the P8-SHED-CM+ group compared with the P8+ group (Fig. 3b). Alizarin red staining showed that there were more calcium deposits in the P8-SHED$\mathrm{CM}+$ group than the $\mathrm{P} 8+$ and $\mathrm{P} 8$-hBMSCs-CM+ groups. Correspondingly, results of the alkaline phosphatase (ALP) staining showed the depth of color among the different groups (Fig. 3c). Collectively, these results suggest that SHED-CM provided a better environment for the survival of hBMSCs, resulting in the retention of osteogenic differentiation potential during long-term expansion in vitro.

\section{Identification of key factors and determination of effective concentrations}

To identify the key factors in SHED supernatant that play a role in preventing senescence and enhancing the osteogenic potential of hBMSCs, we selected previously studied factors secreted by SHED $[25,26]$ or factors regulating the proliferation, stemness, or differentiation of MSCs and compared their expression levels among several oral-derived MSCs and hBMSCs in P3 and P8 using RT-qPCR (Supplemental Data 2). We hypothesized that factors with high expression in SHED and low expression in hBMSCs during series expansion were potential key factors. RT-qPCR results revealed three potential key factors specifically, HGF, SCF, and IGF2. We hypothesized that these factors in SHED-CM may play a role in the delayed senescence and enhanced osteogenic differentiation of hBMSCs.

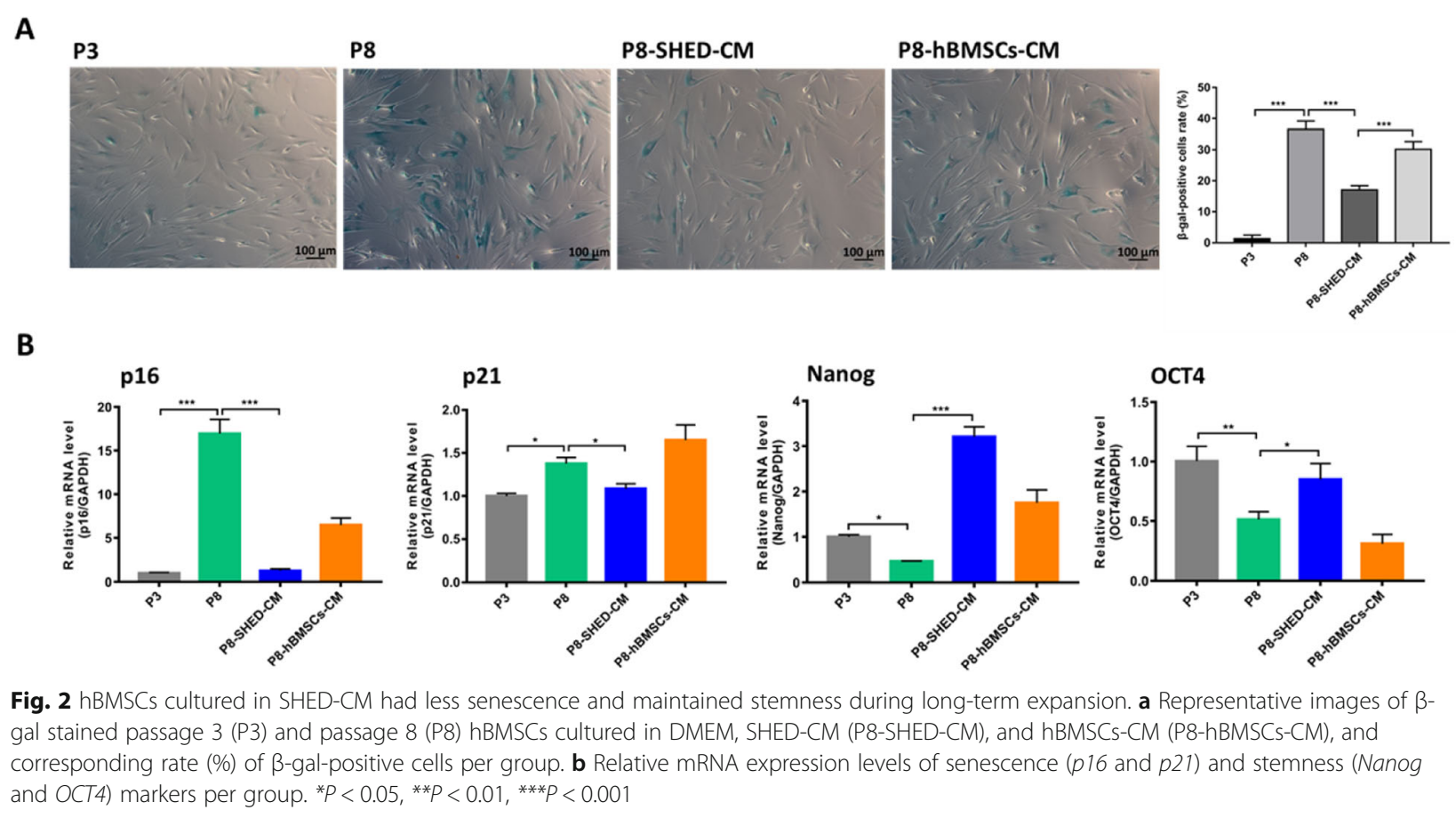




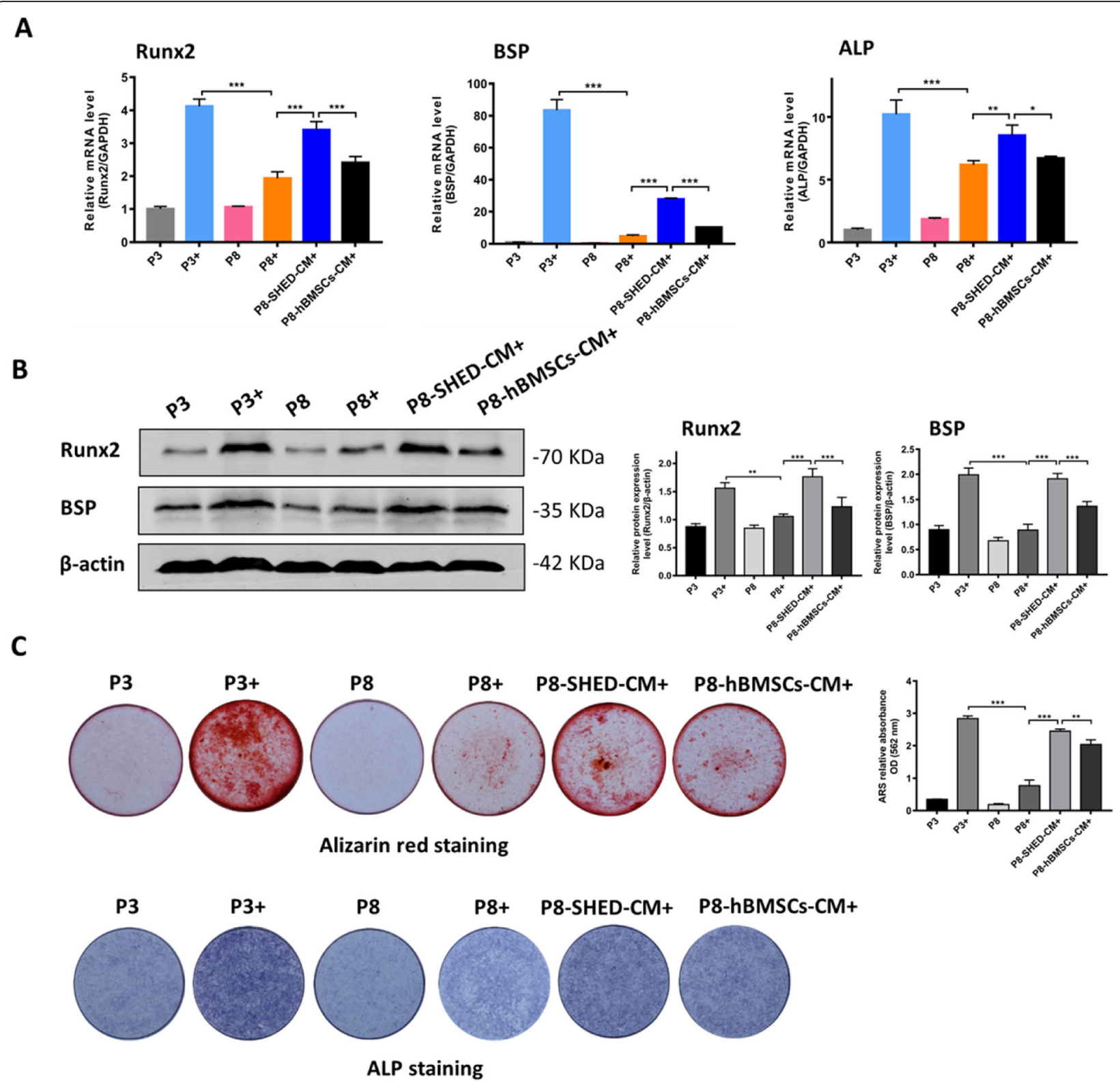

Fig. 3 hBMSCS cultured in SHED-CM had enhanced osteogenic differentiation potential during long-term expansion. Results of the analysis on the expression of osteogenic-related proteins in passage 3 (P3) and passage 8 (P8) hBMSCs cultured in DMEM, SHED-CM (P8-SHED-CM), and hBMSCs-CM (P8-hBMSCs-CM). a Relative mRNA expression levels of Runx2, BSP, and ALP per treatment group after osteogenic induction for 7 days. b Western blot results and relative expression levels of Runx2 and BSP proteins per treatment group after osteogenic induction for 7 days. $\mathbf{c}$ Alizarin Red staining (ARS) after osteogenic induction for 14 days and the corresponding ARS relative absorbance OD of hBMSCs at $562 \mathrm{~nm}$. ALP staining of hBMSCs after osteogenic induction for 14 days. Plus sign indicates with osteogenic induction. ${ }^{*} P<0.05,{ }^{* *} P<0.01,{ }^{* * *} P<0.001$

We attempted to identify these key factors, as well as their effective concentrations, that are beneficial in maintaining the stemness of hBMSCs by culturing hBMSCs in DMEM supplemented with HGF, SCF, and IGF2. The hBMSCs were treated with different concentrations of HGF, SCF, and IGF2 for 3 days. Subsequently, the cell proliferation rate and expression levels of the stemness markers were measured. Furthermore, to determine the effects of HGF, SCF, and IGF2 on the osteogenic differentiation potential of hBMSCs, the 3 days of treatment was followed by 7 days of osteogenic induction. Results of the CFSE assay demonstrated that hBMSCs treated with $50 \mathrm{ng} / \mathrm{ml} \mathrm{HGF,} 100 \mathrm{ng} / \mathrm{ml} \mathrm{HGF}$, $10 \mathrm{ng} / \mathrm{ml} \mathrm{SCF}$, and $10 \mathrm{ng} / \mathrm{ml}$ IGF2 had significantly increased cell proliferation, of which $100 \mathrm{ng} / \mathrm{ml}$ HGF had the strongest effect (Fig. 4a). In addition, the stemness markers, Nanog and OCT4, were highly upregulated in hBMSCs treated with $100 \mathrm{ng} / \mathrm{ml} \mathrm{HGF}$ and $10 \mathrm{ng} / \mathrm{ml} \mathrm{SCF}$ 
A
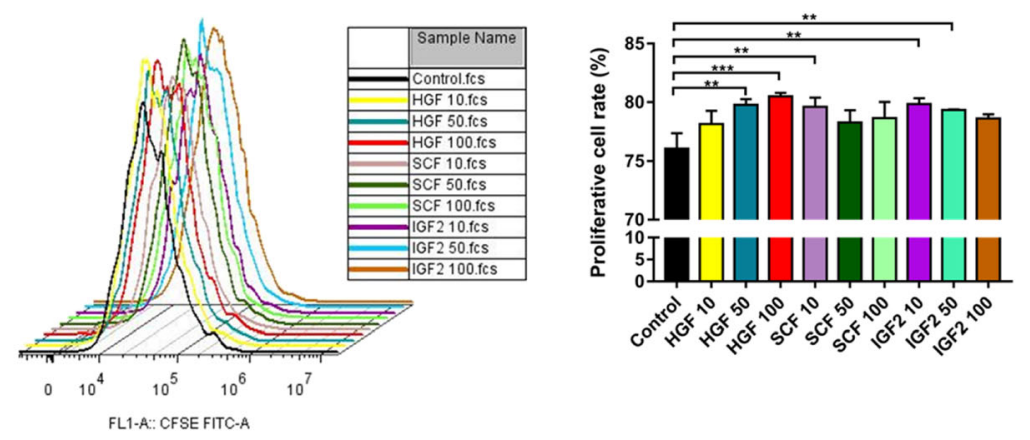

HGF 10
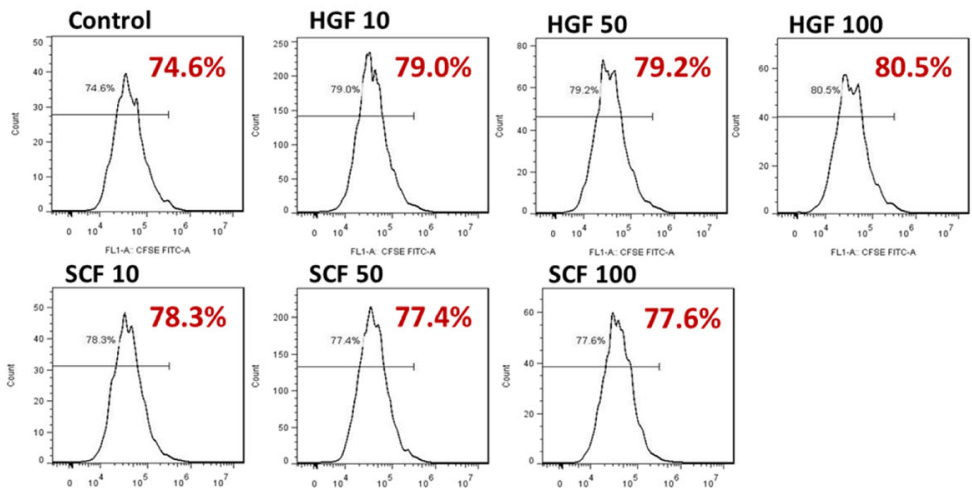

SCF 50

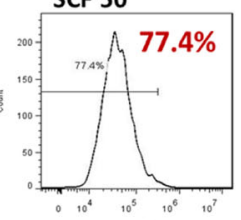

SCF 100

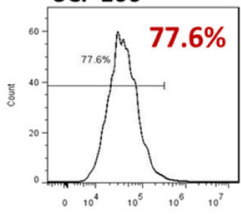

IGF2 50
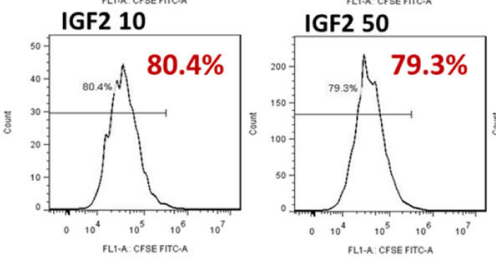

IGF2 100

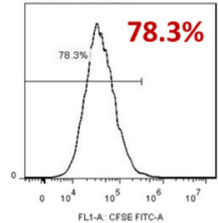

B
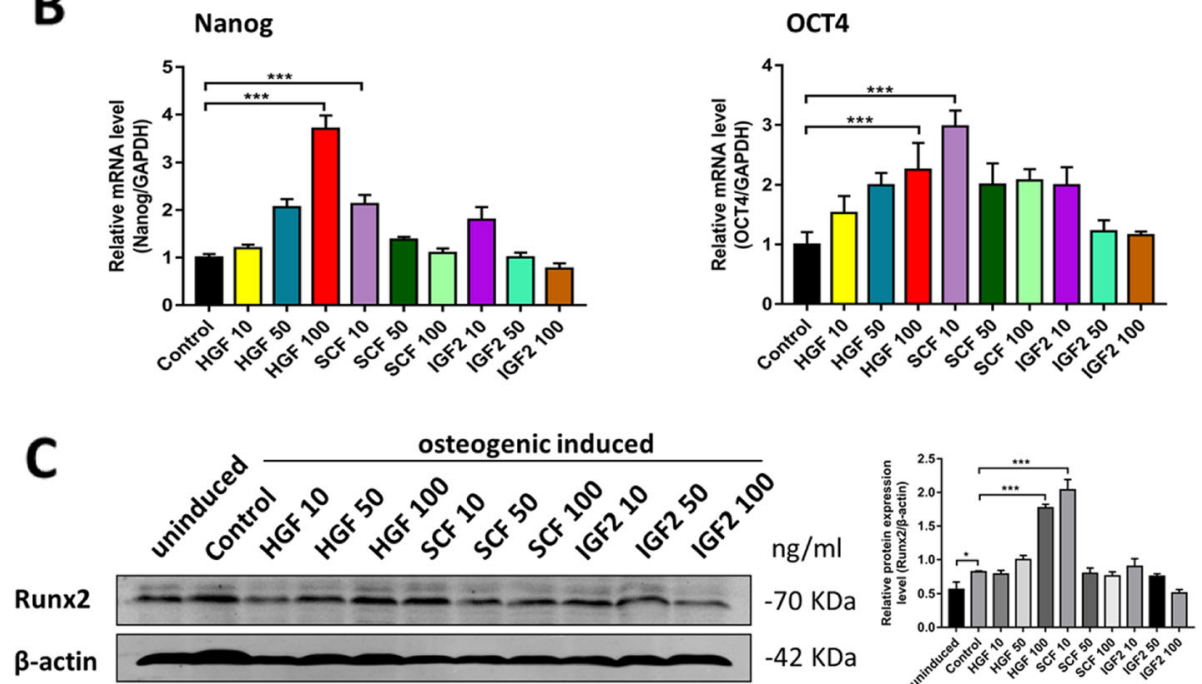

Fig. 4 Identification of key factors and determination of effective concentrations. a Flow cytometry results and individual graphs of CFSE assay, and corresponding proliferative cell rate (\%) of hBMSCs treated with $10 \mathrm{ng} / \mathrm{ml} \mathrm{HGF} \mathrm{(HGF} \mathrm{10),} 50 \mathrm{ng} / \mathrm{ml} \mathrm{HGF} \mathrm{(HGF} \mathrm{50),} 100 \mathrm{ng} / \mathrm{ml} \mathrm{HGF} \mathrm{(HGF} \mathrm{100),}$ $10 \mathrm{ng} / \mathrm{ml} \mathrm{SCF}$ (SCF 10), $50 \mathrm{ng} / \mathrm{ml}$ SCF (SCF 50), $100 \mathrm{ng} / \mathrm{ml} \mathrm{SCF} \mathrm{(SCF} \mathrm{100),} 10 \mathrm{ng} / \mathrm{ml}$ IGF2 (IGF2 10), $50 \mathrm{ng} / \mathrm{ml} \mathrm{IGF2} \mathrm{(IGF2} 50$ ), and 100 ng/ml IGF2 (IGF2 100) compared to the control. c Relative mRNA expression levels of stemness markers, Nanog and OCT4, per treatment group. e Western blot results and corresponding relative expression level of Runx 2 protein per treatment group after 7 days of osteogenic induction. ${ }^{*} P<0.05$, ${ }^{*} P<0.01,{ }^{* * *} P<0.001$ 
(Fig. 4b). Analysis of the osteogenic differentiation potential revealed that $100 \mathrm{ng} / \mathrm{ml} \mathrm{HGF}$ and $10 \mathrm{ng} / \mathrm{ml} \mathrm{SCF}$ greatly enhanced the expression levels of the osteogenicrelated proteins, Runx2 (Fig. 4c). In total, these results demonstrate that $100 \mathrm{ng} / \mathrm{ml} \mathrm{HGF}$ and $10 \mathrm{ng} / \mathrm{ml} \mathrm{SCF}$ can effectively maintain the stemness of hBMSCs, while those treated with IGF2 only had a slight promoting effect or no effect. Therefore, $100 \mathrm{ng} / \mathrm{ml} \mathrm{HGF}$ and $10 \mathrm{ng} /$ $\mathrm{ml} \mathrm{SCF}$ were finally determined for the following experiments, and the effects of the combination of the two factors were also observed.

\section{HGF and SCF delayed senescence and enhanced osteogenic differentiation potential of hBMSCs during long-term expansion}

To determine the molecular mechanism underlying the cytokine-mediated maintenance of stemness, long-term expansion of hBMSCs from P3 to P8 in DMEM supplemented with HGF, SCF, or the combination of these two cytokines were performed. RT-qPCR results revealed that $p 16$ and $p 21$ expression levels significantly decreased while Nanog and OCT4 expression levels increased in P8 hBMSCs treated with $100 \mathrm{ng} / \mathrm{ml} \mathrm{HGF}$ or $10 \mathrm{ng} / \mathrm{ml} \mathrm{SCF}$ (Fig. 5a). $\beta$-gal staining results confirmed that $100 \mathrm{ng} / \mathrm{ml}$ HGF or $10 \mathrm{ng} / \mathrm{ml}$ SCF prevented the senescence of late passage cells, and interestingly, the most significant effect was showed in hBMSCs treated with the combination of $100 \mathrm{ng} / \mathrm{ml} \mathrm{HGF}$ and $10 \mathrm{ng} / \mathrm{ml} \mathrm{SCF}$ (Fig. 5b). In addition, we determined the effects of HGF and SCF on the osteogenic differentiation ability of hBMSCs through alizarin red staining and the expression of the osteogenic protein, Runx2 (Fig. 5c, d). Results showed that hBMSCs cultured in DMEM with $100 \mathrm{ng} / \mathrm{ml} \mathrm{HGF}$ or $10 \mathrm{ng} / \mathrm{ml} \mathrm{SCF}$ after series expansion (P8) retained their excellent osteogenesis ability, which is equivalent to the osteogenesis ability of P3 hBMSCs (Fig. 5d). In total, these results demonstrate that $100 \mathrm{ng} / \mathrm{ml} \mathrm{HGF}$ and $10 \mathrm{ng} / \mathrm{ml}$ SCF delayed senescence and enhanced osteogenic differentiation potential of hBMSCs during long-term expansion, and the most significant results was observed in hBMSCs treated with the combination of the two cytokines.

\section{HGF and SCF reduced ROS accumulation and preserved mitochondrial function of hBMSCs during long-term expansion}

The oxidative status of hBMSCs was also assessed by measuring the ROS production. Results showed that the ROS level of hBMSCs stimulated with $1 \mathrm{mM} \mathrm{H}_{2} \mathrm{O}_{2}$ for 1 $\mathrm{h}$ was significantly increased. hBMSCs in $\mathrm{P} 8 \mathrm{had}$ high ROS levels, while cells treated with $100 \mathrm{ng} / \mathrm{ml}$ HGF or $10 \mathrm{ng} / \mathrm{ml}$ SCF during long-term expansion had lower intracellular ROS levels. Especially the ROS levels in the group treated with the combination of the two cytokines significantly reduced the most (Fig. 6a, b). Long-term expansion in vitro can cause mitochondrial dysfunction, consequently promoting apoptosis. Here, the mitochondrial membrane potential was calculated using JC-1 mitochondrial membrane potential assay. Results showed that the mitochondrial membrane potential decreased in P8 hBMSCs compared with P3 hBMSCs. However, $100 \mathrm{ng} / \mathrm{ml} \mathrm{HGF-} \mathrm{or} 10 \mathrm{ng} / \mathrm{ml}$ SCF-treated hBMSCs exhibited a higher intensity of red fluorescence and a lower intensity of green fluorescence, indicating a higher level of mitochondrial membrane potential (Fig. 6c). Similar results were showed in flow cytometry detection that there were more polarized cells in cytokine-treated groups compared with P8 hBMSCs (Fig. 6d). These results suggest that $100 \mathrm{ng} / \mathrm{ml} \mathrm{HGF}$ and $10 \mathrm{ng} / \mathrm{ml}$ SCF play an important role in preserving the mitochondrial functions of late passage cells.

\section{HGF and SCF preserved the mitochondrial function in hBMSCs via the PI3K/AKT, ERK1/2, and STAT3 signaling pathway}

To determine the mechanism of $100 \mathrm{ng} / \mathrm{ml} \mathrm{HGF}$ or $10 \mathrm{ng} /$ $\mathrm{ml} \mathrm{SCF}$ responsible for maintaining mitochondrial function and stemness, the proteins associated with the PI3K/AKT, ERK1/2, and STAT3 signaling pathways were assessed using Western blot analysis. Results showed that late passage cells had significantly decreased expression of mitochondrialrelated proteins. However, $100 \mathrm{ng} / \mathrm{ml} \mathrm{HGF}$ or $10 \mathrm{ng} / \mathrm{ml} \mathrm{SCF}$ treatments resulted in the increased expression of mitochondrial dynamics-related proteins, Mfn1 and Mfn2, and mitochondrial oxidative stress-related proteins, SOD2 and Catalase, which are the downstream molecules of the PI3K/ AKT and ERK1/2 signaling pathways. Besides, Western blot analysis showed that $100 \mathrm{ng} / \mathrm{ml}$ HGF and $10 \mathrm{ng} / \mathrm{ml} \mathrm{SCF}$ promoted the phosphorylation of AKT and ERK1/2. Therefore, we speculated that HGF and SCF preserved the mitochondrial function of hBMSCs via the PI3K/AKT and ERK1/2 pathways. In addition, the proteins related to the STAT3 pathway were activated and had significantly higher expression in the HGF- and SCF-treated groups than the P8 group (Fig. 7a). The PI3K/AKT and STAT3 pathways regulated the expression levels of the stemness markers, Nanog, and OCT4, and consequently the self-renewal ability of the stem cells, especially the STAT3 pathway, which is involved in regulating the cell cycle and apoptosis.

The PI3K/AKT, ERK1/2, and STAT3 inhibitors have been used in vitro experiment separately. hBMSCs in P3 were treated with DMEM that contained $10 \mu \mathrm{M}$ LY294002 for $6 \mathrm{~h}$ before cytokine treatment to block PI3K/AKT pathway [27-29], $10 \mu \mathrm{MU}$ U126 for $6 \mathrm{~h}$ to block ERK1/2 pathway [27, 30, 31], and $5 \mu \mathrm{M}$ Stattic for $6 \mathrm{~h}$ to block STAT3 pathway [32-34]. Results showed that $100 \mathrm{ng} / \mathrm{ml} \mathrm{HGF}$ and $10 \mathrm{ng} / \mathrm{ml}$ SCF promoted the phosphorylation of AKT, ERK1/2, and STAT3 compared with control group. The phosphorylation levels of AKT, 


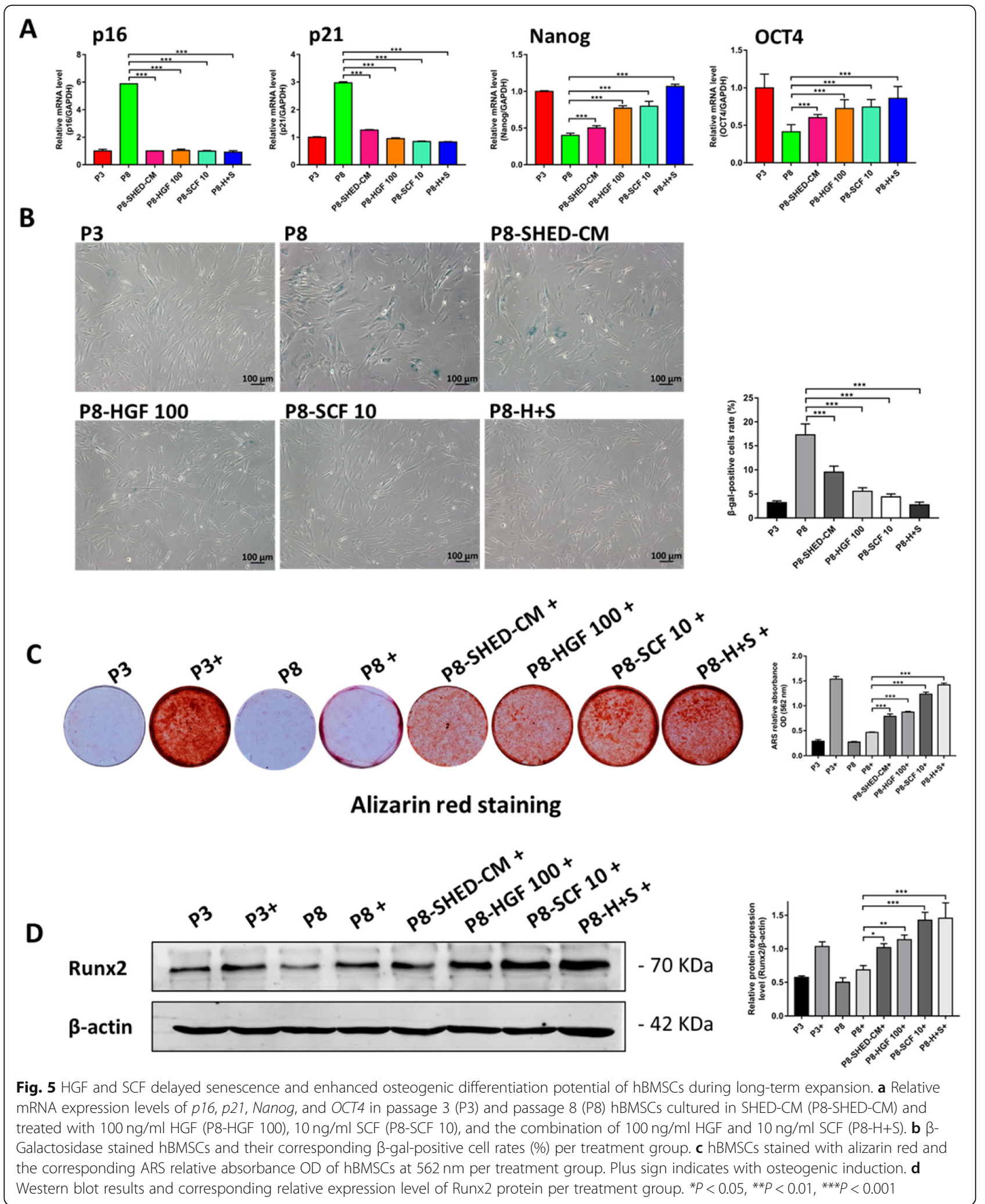

ERK1/2, and STAT3 were all decreased when cells were treated with corresponding inhibitors, meanwhile the expression of mitochondrial oxidative stress-related proteins Catalase and SOD2 in cells were decreased by treatment of LY294002, U0126, and Stattic (Fig. 7c-e). Taken together, these results further verify that HGF 
A

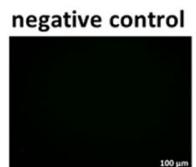

positive control
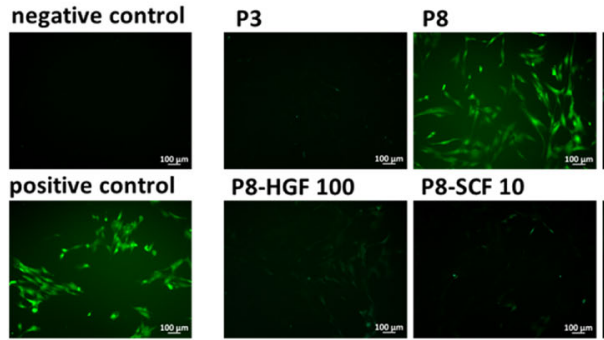

P8-SHED-CM

P8-HGF 100

P8-SCF 10

$\mathrm{P} 8-\mathrm{H}+\mathrm{S}$
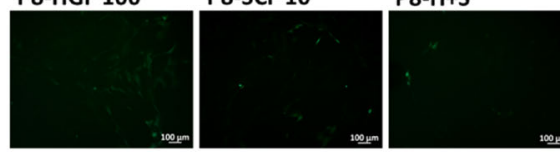

B
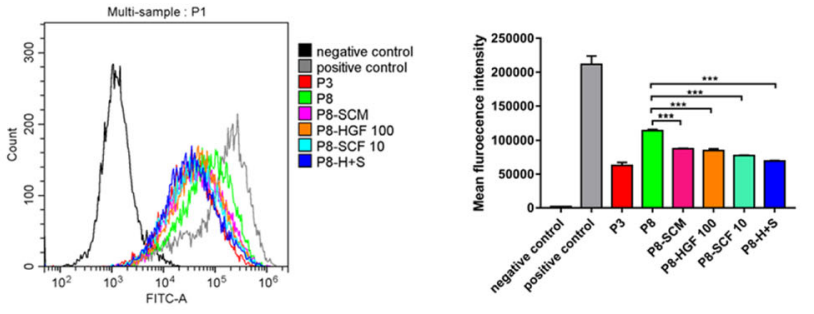

C
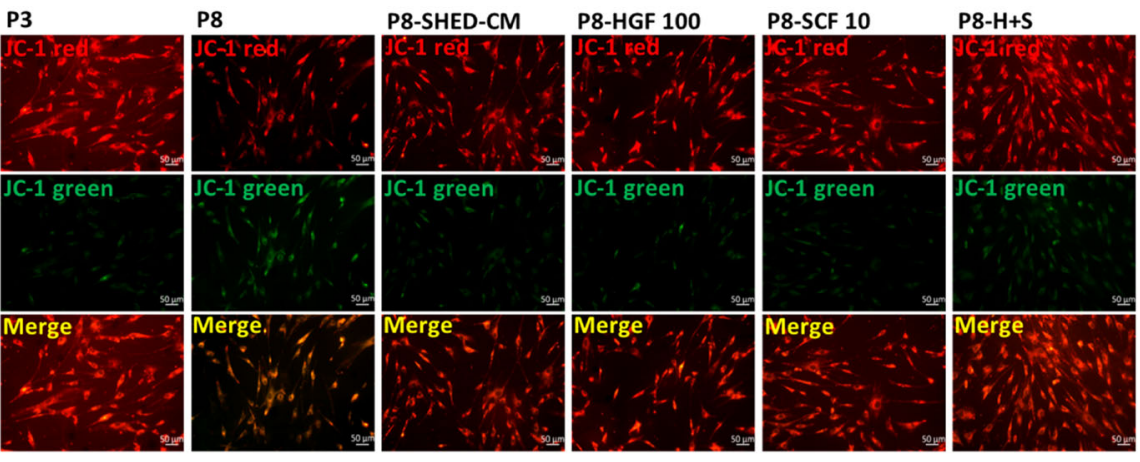

D
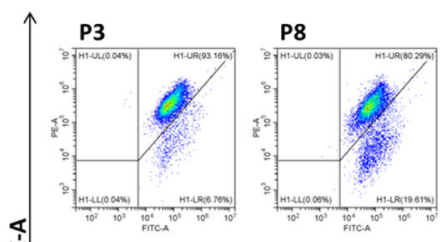

P8-SHED-CM
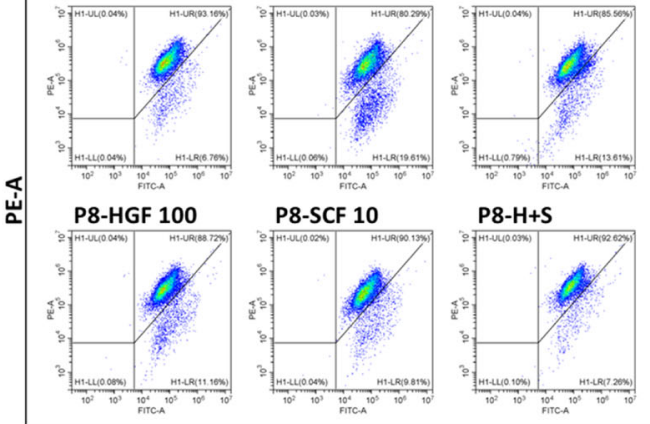

P8-H+S
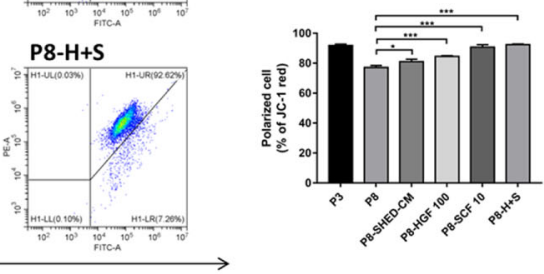

Fig. 6 HGF and SCF reduced ROS accumulation and preserved mitochondrial function of hBMSCs during long-term expansion. a Representative images of ROS levels in negative control, positive control (stimulated with $1 \mathrm{mM} \mathrm{H}_{2} \mathrm{O}_{2}$ for $1 \mathrm{~h}$ ), passage 3 (P3), and passage 8 (P8) hBMSCs cultured in SHED-CM (P8-SHED-CM) and treated with $100 \mathrm{ng} / \mathrm{ml} \mathrm{HGF} \mathrm{(P8-HGF} \mathrm{100),} 10 \mathrm{ng} / \mathrm{ml}$ SCF (P8-SCF 10), and the combination of $100 \mathrm{ng} / \mathrm{ml}$ HGF and $10 \mathrm{ng} / \mathrm{ml} \mathrm{SCF}(\mathrm{P} 8-\mathrm{H}+\mathrm{S})$. b Flow cytometry results of ROS levels and mean fluorescent intensity in hBMSCs per treatment group. $\mathbf{c}$ Representative images of mitochondrial membrane potential in hBMSCs per treatment group detected by JC-1 probe. The J-aggregates produced red fluorescence (JC-1 red); the monomer produced green fluorescence (JC-1 green). d Flow cytometry results of mitochondrial membrane potential and corresponding percentage (\%) of polarized cell per treatment group detected by JC-1 probe. ${ }^{*} P<0.05,{ }^{* * *} P<0.001$

and SCF treatment upregulated the expression of mitochondrial-related proteins Catalase and SOD2 via the PI3K/AKT, ERK1/2, and STAT3 signaling pathways, thereby preserving the mitochondrial functions and preventing the senescence of hBMSCs during long-term expansion. 


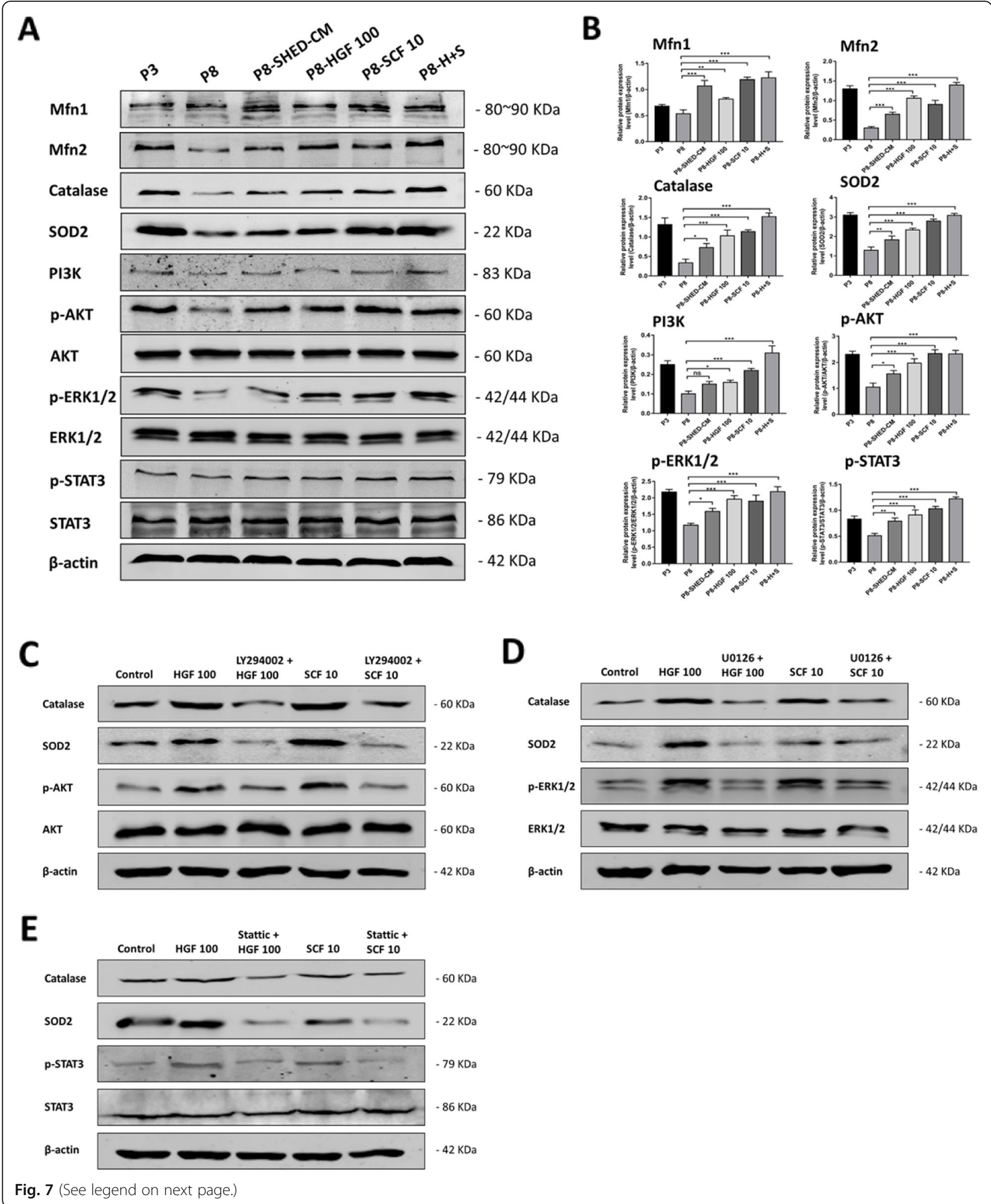


(See figure on previous page.)

Fig. 7 HGF and SCF preserved the mitochondrial function in hBMSCS via the PI3K/AKT, ERK1/2, and STAT3 signaling pathway. a Western blot results of the expression of mitochondrial-relative proteins (Mfn1, Mfn2, SOD2, and Catalase) and the PI3K AKT, Erk1/2, and STAT3 signaling pathway-related proteins in passage 3 (P3) and passage 8 (P8) hBMSCs cultured in SHED-CM (P8-SHED-CM) and treated with $100 \mathrm{ng} / \mathrm{ml}$ (P8-HGF 100), $10 \mathrm{ng} / \mathrm{ml}$ SCF (P8-SCF 10), and the combination of $100 \mathrm{ng} / \mathrm{ml} \mathrm{HGF}$ and $10 \mathrm{ng} / \mathrm{ml} \mathrm{SCF}(\mathrm{P} 8-\mathrm{H}+\mathrm{S})$. b Relative expression levels of the protein showed in the Western blot. ns, not significant. c Western blot results of the expression of mitochondrial oxidative stress-related proteins, Catalase and SOD2, and the PI3K/AKT signaling pathway-related proteins in P3 hBMSCs treated with $100 \mathrm{ng} / \mathrm{ml} \mathrm{HGF,} 10 \mu \mathrm{M}$ LY294002 plus $100 \mathrm{ng} / \mathrm{ml} \mathrm{HGF}$, $10 \mathrm{ng} / \mathrm{ml} \mathrm{SCF}$, and $10 \mu \mathrm{M} \mathrm{LY} 294002$ plus $10 \mathrm{ng} / \mathrm{ml} \mathrm{SCF}$. d Western blot results of the expression of mitochondrial oxidative stress-related proteins, Catalase and SOD2, and the PI3K/AKT signaling pathway-related proteins in P3 hBMSCs treated with $100 \mathrm{ng} / \mathrm{ml} \mathrm{HGF,} 10$ HM U0126 plus $100 \mathrm{ng} / \mathrm{ml}$ HGF, $10 \mathrm{ng} / \mathrm{ml} \mathrm{SCF}$, and $10 \mu \mathrm{M} \cup 0126$ plus $10 \mathrm{ng} / \mathrm{ml} \mathrm{SCF}$. e Western blot results of the expression of mitochondrial oxidative stress-related proteins, Catalase and SOD2, and the PI3K/AKT signaling pathway-related proteins in P3 hBMSCs treated with $100 \mathrm{ng} / \mathrm{ml} \mathrm{HGF,} 5 \mu$ M Stattic plus $100 \mathrm{ng} / \mathrm{ml} \mathrm{HGF}, 10 \mathrm{ng} / \mathrm{ml} \mathrm{SCF}$, and $10 \mu \mathrm{M}$ Stattic plus $10 \mathrm{ng} / \mathrm{ml} \mathrm{SCF} .{ }^{*} P<0.05,{ }^{* *} P<0.01,{ }^{* * *} P<0.001$

\section{Discussion}

In general, it is necessary to expand MSCs in vitro and obtain a sufficient quantity for use in clinical treatments. However, this is often difficult due to cell senescence, which is typically characterized by cell cycle arrest in G0/G1 phase (Fig. 1b), increased $\beta$-galactosidase activity (Fig. 2a), and upregulated expression of genes involved in cell cycle regulation, such as $p 16$ and $p 21$ (Fig. 2b). In the present study, we demonstrated that the microenvironment provided by SHED significantly reduced the senescence of hBMSCs after serial expansion.

Cell senescence also seriously affects the proliferation and functional activities of MSCs. To date, bone-related diseases are the primary focus in the clinical application and research of MSCs for therapy. However, the main challenge is how to reconstruct vascularized bone with physiologic structure and function. Here, we found that compared with P3 hBMSCs, P8 hBMSCs had almost negligible osteogenesis potential in vitro (Fig. 3). To address this, we focused on improving the microenvironment of MSCs in vitro by culturing hBMSCs in SHED-CM and identifying the key factors influencing the state of MSCs.

The formation of new blood vessels is a critical process during bone reconstruction and plays a major role in creating a niche for both the bone-forming skeletal stem cells and blood-forming hematopoietic stem cells [35, 36]. Our study revealed that transplanted MSCs in an aging state had significantly impaired bonepromoting capacity and significantly decreased proangiogenic capacity after series expansion (Supplemental Data 3). Senescent MSCs cannot induce angiogenesis in the damaged area, leading to local oxygen and nutrient deficiencies and exacerbated inflammation, which further impairs the activity and function of MSCs. Ultimately, this results in significantly decreased transplantation efficacy [37-39]. We also confirmed that SHED-CM enhanced the osteogenesis ability and delayed the senescence of hBMSCs, thereby resulting in better angiogenesis. The expansion of hBMSCs without loss of function provides new insights in creating strategies for the transplantation of MSCs and subsequent use in clinical therapy.
In this study, we demonstrated that SHED-CM could provide a better microenvironment for hBMSCs and maintain their stemness during long-term expansion. We also identified several key factors and possible mechanisms responsible for maintaining the stemness of hBMSCs and, consequently, design new methods to optimize the long-term expansion of MSCs in vitro.

HGF and SCF have attracted much attention because of their prominent expression in SHED. We observed that the addition of these factors to the culture medium significantly delayed the senescence (Fig. 5b), enhanced the osteogenic potential (Fig. 5c, d), and significantly reduced the accumulation of ROS in aging MSCs after long-term expansion (Fig. 6a, b). Excessive ROS in cells can activate stress-related signaling pathways, mediate mitochondrial inflammatory responses, cause mitochondrial function damage, and induce apoptosis [40-42]. Therefore, we further investigated the effects of HGF and SCF on the regulation of mitochondrial membrane potential (Fig. 6c, d), which is an important mitochondrial function that reflects the apoptotic state of cells. HGF and SCF enhanced the membrane potential of MSCs after series amplification and increased the production of Catalase and SOD2 that can catalyze ROS. Simultaneously, HGF and SCF upregulated the expression of mitochondrial dynamics-related proteins, specifically the fusion proteins Mfn1 and Mfn2, and increased the cellular oxidative phosphorylation and ATP synthesis $[43,44]$, which indicates that the mitochondrial activity of MSCs was effectively enhanced [45-47].

We also confirmed that HGF and SCF increased the expression of mitochondrial-associated proteins, Catalase and SOD2, via activation of the PI3K/AKT and ERK1/2 signaling pathways, which have anti-apoptotic roles and regulate the apoptosis-related proteins, $\mathrm{Bcl}$ and Bax [48]. HGF and SCF modulated the osteogenic differentiation of MSCs through the ERK1/2 signaling pathway $[49,50]$, effectively promoting the timely removal of excessive ROS in cells, reducing mitochondrial damage, and delaying cellular senescence. In addition, HGF and SCF can promote the self-renewal capacity of MSCs by regulating the expression of the cell cycle-related 
protein, p21, and the stemness markers, Nanog and OCT4, through the STAT3 pathway [51, 52]. Collectively, the findings of this study demonstrated that HGF and SCF have a potential application in studies focused on delaying cellular senescence of MSCs.

In this study, we have only confirmed that HGF and SCF have the effect of delaying senescence of MSCs after long-term expansion. However, there are still many other factors and molecular mechanisms waiting to be discovered. Furthermore, there are many structural and functional imbalances occur during the process of cellular senescence. We can also find the mechanism of HGF and SCF in maintaining stemness from other aspects, such as cell autophagy, DNA damage, and so on. Maybe we can find a new way to solve the problem of MSCs senescence from these areas.

\section{Conclusion}

Both HGF and SCF are key factors in maintaining the stemness of hBMSCs by preserving mitochondrial function through the expression of proteins associated with the PI3K/AKT, ERK1/2, and STAT3 signaling pathways. This study provides new insights into the antisenescence capability of HGF and SCF, as well as new evidence for their potential application in optimizing the long-term culture of MSCs.

\section{Supplementary information}

Supplementary information accompanies this paper at https://doi.org/10. 1186/s13287-020-01830-4.

Additional file 1: Supplemental Data 1. Characterization of SHED.

Additional file 2: Supplemental Data 2. Identification of key factors using RT-qPCR. Table 2. Primer sequences used in reverse transcription quantitative PCR (RT-qPCR)

Additional file 3: Supplemental Data 3. hBMSCs cultured in SHED-CM had enhanced pro-angiogenic capacity during long-term expansion.

\section{Abbreviations}

MSCs: Mesenchymal stem cells; SHED: Stem cells from human exfoliated deciduous teeth; hBMSCs: Human bone marrow mesenchymal stem cells; P3: Passage 3; P8: Passage 8; SHED-CM: Conditioned medium from SHED; RTGPCR: Reverse transcription quantitative PCR; ALP: Alkaline phosphatase; HGF: Hepatocyte growth factor; SCF: Stem cell factor; CGVHD: Chronic graft versus host diseases; ECM: Extracellular matrix; IGF2: Insulin-like growth factor 2; hBMSCs-CM: Conditioned medium from hBMSCs; CFU: Colony-forming unit; PFA: Paraformaldehyde; PI: Propidium iodide; $\beta$-gal: $\beta$-Galactosidase; SDS-PAGE: Sodium dodecyl sulfate polyacrylamide gel electrophoresis; NC: Nitrocellulose; Mfn1: Mitofusin 1; Mfn2: Mitofusin 2; ARS: Alizarin red staining; ANOVA: One-way analysis of variance
\end{abstract}

\section{Acknowledgements}

This work was supported by the National Natural Science Foundation of China (No. 81530069) and the Guangdong Innovative Research Team program (No. 2009010058). The authors would also like to thank all the staff at the department of Guangdong Provincial Key Laboratory of Stomatology in Sun Yat-sen University.

\section{Authors' contributions}

Yan Wang was responsible for the conception, study design, and final decision of the manuscript. Zeyuan Cao and Yunyi Xie were responsible for the study design, data collection and analysis, and manuscript writing and revision. Le Yu and Yi Li contributed to the experimental studies and data collection. Zeyuan Cao, Yunyi Xie, Le Yu, and Yi Li were responsible for the data analysis and interpretation. The final version of the manuscript was read and approved by all the authors.

\section{Funding}

This study was supported by grants from the National Natural Science Foundation of China (No. 81530069) and the Guangdong Innovative Research Team program (No. 2009010058).

\section{Availability of data and materials}

The datasets generated and/or analyzed during the current study are available from the corresponding author on reasonable request.

\section{Ethics approval and consent to participate}

The informed consents were obtained from the parents or guardians, and the ethics approval was required according to the guidelines from the Ethics Committee of Hospital of Stomatology in Sun Yat-sen University. All the procedures described in this report were approved by the Ethics Committee of Hospital of Stomatology in Sun Yat-sen University.

\section{Consent for publication}

Not applicable.

\section{Competing interests}

The authors declare that they have no competing interests.

Received: 12 February 2020 Revised: 23 May 2020

Accepted: 13 July 2020 Published online: 31 July 2020

\section{References}

1. Liu S, Liu D, Chen C, Hamamura K, Moshaverinia A, Yang R, et al. MSC transplantation improves osteopenia via epigenetic regulation of notch signaling in lupus. Cell Metab. 2015;22:606-18.

2. McGonagle $\mathrm{D}$, Baboolal TG, Jones $\mathrm{E}$. Native joint-resident mesenchymal stem cells for cartilage repair in osteoarthritis. Nat Rev Rheumatol. 2017;13: 719-30.

3. Mesentier-Louro LA, Teixeira-Pinheiro LC, Gubert F, Vasques JF, Silva-Junior AJ, Chimeli-Ormonde L, et al. Long-term neuronal survival, regeneration, and transient target reconnection after optic nerve crush and mesenchymal stem cell transplantation. Stem Cell Res Ther. 2019;10:121.

4. Tsai MJ, Liou DY, Lin YR, Weng CF, Huang MC, Huang WC, et al. Attenuating spinal cord injury by conditioned medium from bone marrow mesenchymal stem cells.J Clin Med. 2018:8:23.

5. Gu LH, Zhang TT, Li Y, Yan HJ, Qi H, Li FR. Immunogenicity of allogeneic mesenchymal stem cells transplanted via different routes in diabetic rats. Cell Mol Immunol. 2015;12:444-55.

6. Konala VBR, Mamidi MK, Bhonde R, Das AK, Pochampally R, Pal R. The current landscape of the mesenchymal stromal cell secretome: a new paradigm for cell-free regeneration. Cytotherapy. 2016;18:13-24.

7. Gao L, Zhang Y, Hu B, Liu J, Kong P, Lou S, et al. Phase II multicenter, randomized, double-blind controlled study of efficacy and safety of umbilical cord-derived mesenchymal stromal cells in the prophylaxis of chronic graft-versus-host disease after HLA-haploidentical stem-cell transplantation. J Clin Oncol. 2016:34:2843-50.

8. Ciccocioppo R, Corazza GR. Mesenchymal stem cells for fistulising Crohn's disease. Lancet. 2016;388:1251-2.

9. Bakopoulou A, Apatzidou D, Aggelidou E, Gousopoulou E, Leyhausen G, Volk J, et al. Isolation and prolonged expansion of oral mesenchymal stem cells under clinical-grade, GMP-compliant conditions differentially affects "stemness" properties. Stem Cell Res Ther. 2017:8:247.

10. Bunpetch V, Zhang ZY, Zhang X, Han S, Zongyou P, Wu H, et al. Strategies for MSC expansion and MSC-based microtissue for bone regeneration. Biomaterials. 2019;196:67-79.

11. Lin H, Sohn J, Shen H, Langhans MT, Tuan RS. Bone marrow mesenchymal stem cells: aging and tissue engineering applications to enhance bone healing. Biomaterials. 2019;203:96-110. 
12. Baker N, Boyette LB, Tuan RS. Characterization of bone marrow-derived mesenchymal stem cells in aging. Bone. 2015;70:37-47.

13. Scadden DT. Nice neighborhood: emerging concepts of the stem cell niche. Cell. 2014;157:41-50

14. Rayagiri SS, Ranaldi D, Raven A, Mohamad Azhar NIF, Lefebvre O, Zammit PS, et al. Basal lamina remodeling at the skeletal muscle stem cell niche mediates stem cell self-renewal. Nat Commun. 2018;9:1075.

15. Chen KY, Srinivasan T, Tung KL, Belmonte JM, Wang L, Murthy PKL, et al. A notch positive feedback in the intestinal stem cell niche is essential for stem cell self-renewal. Mol Syst Biol. 2017;13:927.

16. Engler AJ, Sen S, Sweeney HL, Discher DE. Matrix elasticity directs stem cell lineage specification. Cell. 2006;126:677-89.

17. Su N, Gao P, Wang K, Wang J, Zhong Y, Luo Y. Fibrous scaffolds potentiate the paracrine function of mesenchymal stem cells: a new dimension in cellmaterial interaction. Biomaterials. 2017;141:74-85.

18. Rustad KC, Wong W, Sorkin M, Glotzbach JP, Major MR, Rajadas J, et al. Enhancement of mesenchymal stem cell angiogenic capacity and stemness by a biomimetic hydrogel scaffold. Biomaterials. 2012;33:80-90.

19. Wu L, Magaz A, Wang T, Liu C, Darbyshire A, Loizidou M, et al. Stiffness memory of indirectly 3D-printed elastomer nanohybrid regulates chondrogenesis and osteogenesis of human mesenchymal stem cells. Biomaterials. 2018;186:64-79.

20. Wen L, Wang Y, Wen N, Yuan G, Wen M, Zhang L, et al. Role of endothelial progenitor cells in maintaining stemness and enhancing differentiation of mesenchymal stem cells by indirect cell-cell interaction. Stem Cells Dev. 2016;25:123-38

21. Miura M, Gronthos S, Zhao M, Lu B, Fisher LW, Robey PG, et al. SHED: stem cells from human exfoliated deciduous teeth. Proc Natl Acad Sci U S A. 2003;100:5807-12.

22. Kunimatsu R, Nakajima $K$, Awada $T$, Tsuka $Y$, Abe $T$, Ando $K$, et al. Comparative characterization of stem cells from human exfoliated deciduous teeth, dental pulp, and bone marrow-derived mesenchymal stem cells. Biochem Biophys Res Commun. 2018;501:193-8.

23. Bauer D, Werth F, Nguyen HA, Kiecker F, Eberle J. Critical role of reactive oxygen species (ROS) for synergistic enhancement of apoptosis by vemurafenib and the potassium channel inhibitor TRAM-34 in melanoma cells. Cell Death Dis. 2017;8:e2594.

24. Vessey W, Perez-Miranda A, Macfarquhar R, Agarwal A, Homa S. Reactive oxygen species in human semen: validation and qualification of a chemiluminescence assay. Fertil Steril. 2014:102:1576-83.

25. Mussano F, Genova T, Petrillo S, Roato I, Ferracini R, Munaron L. Osteogenic differentiation modulates the cytokine, chemokine, and growth factor profile of ASCs and SHED. Int J Mol Sci. 2018;19:1454.

26. Matsushita $Y$, Ishigami M, Matsubara $K$, Kondo M, Wakayama H, Goto H, et al. Multifaceted therapeutic benefits of factors derived from stem cells from human exfoliated deciduous teeth for acute liver failure in rats. $J$ Tissue Eng Regen Med. 2017;11:1888-96.

27. Chang P, Zhang B, Shao L, Song W, Shi W, Wang L, et al. Mesenchymal stem cells over-expressing $\mathrm{cxcl} 12$ enhance the radioresistance of the small intestine. Cell Death Dis. 2018;9:154

28. Yin L, Huang D, Liu X, Wang Y, Liu J, Liu F, et al. Omentin-1 effects on mesenchymal stem cells: proliferation, apoptosis, and angiogenesis in vitro. Stem Cell Res Ther. 2017;8:224.

29. Lee HJ, Kim SN, Jeon MS, Yi T, Song SU. ICOSL expression in human bone marrow-derived mesenchymal stem cells promotes induction of regulatory T cells. Sci Rep. 2017;7:44486.

30. Zhang S, Chuah SJ, Lai RC, Hui J, Lim SK, Toh WS. MSC exosomes mediate cartilage repair by enhancing proliferation, attenuating apoptosis and modulating immune reactivity. Biomaterials. 2018;156:16-27.

31. Lu ZY, Chen WC, Li YH, Li L, Zhang H, Pang Y, et al. TNF-alpha enhances vascular cell adhesion molecule-1 expression in human bone marrow mesenchymal stem cells via the NF-kappaB, ERK and JNK signaling pathways. Mol Med Rep. 2016;14:643-8.

32. Ning T, Guo J, Zhang K, Li K, Zhang J, Yang Z, et al. Nanosecond pulsed electric fields enhanced chondrogenic potential of mesenchymal stem cells via JNKVCREB-STAT3 signaling pathway. Stem Cell Res Ther. 2019;10:45.

33. Lin L, Jou D, Wang Y, Ma H, Liu T, Fuchs J, et al. STAT3 as a potential therapeutic target in ALDH+ and CD44+/CD24+ stem cell-like pancreatic cancer cells. Int J Oncol. 2016;49:2265-74.
34. He N, Kong Y, Lei X, Liu Y, Wang J, Xu C, et al. MSCs inhibit tumor progression and enhance radiosensitivity of breast cancer cells by downregulating Stat3 signaling pathway. Cell Death Dis. 2018;9:1026.

35. Verrier S, Alini M, Alsberg E, Buchman SR, Kelly D, Laschke MW, et al. Tissue engineering and regenerative approaches to improving the healing of large bone defects. Eur Cell Mater. 2016;32:87-110.

36. Inglis S, Kanczler JM, Oreffo R. 3D human bone marrow stromal and endothelial cell spheres promote bone healing in an osteogenic niche. FASEB J. 2019:33:3279-90.

37. Liang $X$, Ding $Y$, Lin F, Zhang $Y$, Zhou $X$, Meng $Q$, et al. Overexpression of ERBB4 rejuvenates aged mesenchymal stem cells and enhances angiogenesis via PI3K/AKT and MAPK/ERK pathways. FASEB J. 2019;33:455970.

38. Jiang L, Zhang W, Wei L, Zhou Q, Yang G, Qian N, et al. Early effects of parathyroid hormone on vascularized bone regeneration and implant osseointegration in aged rats. Biomaterials. 2018;179:15-28.

39. Choudhery MS, Khan M, Mahmood R, Mehmood A, Khan SN, Riazuddin S. Bone marrow derived mesenchymal stem cells from aged mice have reduced wound healing, angiogenesis, proliferation and anti-apoptosis capabilities. Cell Biol Int. 2012;36:747-53.

40. Cheng Y, Dai C, Zhang J. SIRT3-SOD2-ROS pathway is involved in linaloolinduced glioma cell apoptotic death. Acta Biochim Pol. 2017:64:343-50.

41. Ganta KK, Mandal A, Chaubey B. Depolarization of mitochondrial membrane potential is the initial event in non-nucleoside reverse transcriptase inhibitor efavirenz induced cytotoxicity. Cell Biol Toxicol. 2017;33:69-82.

42. Fu B, Zhao J, Peng W, Wu H, Zhang Y. Resveratrol rescues cadmiuminduced mitochondrial injury by enhancing transcriptional regulation of PGC-1alpha and SOD2 via the Sirt3/FoxO3a pathway in TCMK-1 cells. Biochem Biophys Res Commun. 2017;486:198-204.

43. Gomes LC, Di Benedetto G, Scorrano L. During autophagy mitochondria elongate, are spared from degradation and sustain cell viability. Nat Cell Biol. 2011;13:589-98.

44. Mitra K, Wunder C, Roysam B, Lin G, Lippincott-Schwartz J. A hyperfused mitochondrial state achieved at G1-S regulates cyclin $E$ buildup and entry into S phase. Proc Natl Acad Sci U S A. 2009;106:11960-5.

45. Lu Y, Chen L, Ye J, Chen C, Zhou Y, Li K, et al. Surgery/Anesthesia disturbs mitochondrial fission/fusion dynamics in the brain of aged mice with postoperative delirium. Aging (Albany). 2020;12:844-65.

46. Hall AR, Burke N, Dongworth RK, Kalkhoran SB, Dyson A, Vicencio JM, et al. Hearts deficient in both Mfn1 and Mfn2 are protected against acute myocardial infarction. Cell Death Dis. 2016;7:e2238.

47. Chen H, Detmer SA, Ewald AJ, Griffin EE, Fraser SE, Chan DC. Mitofusins Mfn1 and Mfn2 coordinately regulate mitochondrial fusion and are essential for embryonic development. J Cell Biol. 2003;160:189-200.

48. Zhong $W$, Zhao Y, Tian Y, Chen M, Lai X. The protective effects of HGF against apoptosis in vascular endothelial cells caused by peripheral vascular injury. Acta Biochim Biophys Sin (Shanghai). 2018;50:701-8.

49. Wen Q, Zhang S, Du X, Wang R, Li Y, Liu H, et al. The multiplicity of infection-dependent effects of recombinant adenovirus carrying HGF gene on the proliferation and osteogenic differentiation of human bone marrow mesenchymal stem cells. Int J Mol Sci. 2018;19:734.

50. Li X, Zhang Y, Liang Y, Cui Y, Yeung SC, Ip MS, et al. iPSC-derived mesenchymal stem cells exert SCF-dependent recovery of cigarette smokeinduced apoptosis/proliferation imbalance in airway cells. J Cell Mol Med. 2017:21:265-77.

51. Zhang $Y, X u$ W, Guo H, Zhang $Y$, He $Y$, Lee SH, et al. NOTCH1 signaling regulates self-renewal and platinum chemoresistance of cancer stem-like cells in human non-small cell lung cancer. Cancer Res. 2017;77:3082-91.

52. Zhang Z, Zhu $P$, Zhou Y, Sheng Y, Hong Y, Xiang D, et al. A novel slugcontaining negative-feedback loop regulates SCF/c-Kit-mediated hematopoietic stem cell self-renewal. Leukemia. 2017:31:403-13.

\section{Publisher's Note}

Springer Nature remains neutral with regard to jurisdictional claims in published maps and institutional affiliations. 